\title{
Lumen
}

Selected Proceedings from the Canadian Society for Eighteenth-Century Studies

\section{Expecting the Unexpected: Haydn’s Three-Part Expositions}

\section{Alexander Raymond Ludwig}

Volume 32, 2013

URI : https://id.erudit.org/iderudit/1015482ar

DOI : https://doi.org/10.7202/1015482ar

Aller au sommaire du numéro

Éditeur(s)

Canadian Society for Eighteenth-Century Studies / Société canadienne d'étude du dix-huitième siècle

ISSN

1209-3696 (imprimé)

1927-8284 (numérique)

Découvrir la revue

Citer cet article

Ludwig, A. R. (2013). Expecting the Unexpected: Haydn’s Three-Part

Expositions. Lumen, 32, 31-40. https://doi.org/10.7202/1015482ar d'utilisation que vous pouvez consulter en ligne.

https://apropos.erudit.org/fr/usagers/politique-dutilisation/ 


\title{
Expecting the Unexpected: Haydn's Three-Part Expositions
}

\author{
Alexander Raymond Ludwig \\ Boston College
}

In 1929, Sir Donald Francis Tovey, a British music critic and theorist, described the unusual nature of Op. 20, no. 2 , in $\mathrm{C}$ major, an early string quartet written by Joseph Haydn:

Among all these luxurious effects, the quieter passages stand out in exquisite relief, especially the purple patch of the modulation...in the course of the 'second subject'...It is treated here exactly as it would be treated in Beethoven. ${ }^{1}$

This description features Tovey's first analytical use of the term "purple patch." In his formulation, a purple patch was a modulation to an unexpected harmonic area-a practice that became commonplace in the early Romantic period, especially in the music of Ludwig van Beethoven and Franz Schubert. ${ }^{2}$ But Tovey described this concept in

1. Donald Francis Tovey, "Haydn's Chamber Music," in Cobbett's Cyclopedic Survey of Chamber Music, vol. I, A-H, ed. William Wilson Cobbett (London: Oxford University Press, 1929), 41-42 (emphasis added). Later published in The Mainstream of Music and Other Essays (London: Oxford University Press, 1949), 1-64. In addition to op. 20 , no. 2, Tovey described a similar flatward slide-albeit without the term 'purple patch'-in Haydn's op. 17, no. 6: "In this quartet the plunging of the 'second subject' into $\mathrm{C}$ major where A major is expected is a Beethoven-Schubert device executed quite broadly (38-39)."

2. For more on the purple patch in Schubert, see James Webster, "Schubert's Sonata Form and Brahms's First Maturity," $19^{\text {th }}$-Century Music 2.1 (July 1978): 18-35. Although the impact of Haydn's use of the purple patch on composers of the next generation-especially Beethoven and Schubert-remains to be investigated, it is clear that this device anticipated broad harmonic developments in the nineteenth century. 
string quartets by Joseph Haydn, predating the Romantic era in some cases by fifty years. The fact that Tovey first applied the purple patch to music written by Haydn-not Schubert or Beethoven-inspired the current investigation of the connection between Tovey's purple patches and Haydn's string quartets.

The longstanding affiliation of the color purple with emperors and the aristocracy alike stems from its extremely rare and expensive dye. The color, however, has connotations besides those of its royal origins: the phrase "purple prose," which refers to an elaborate or florid literary passage that stands apart from its surrounding material, seems to have inspired Tovey. He appropriated this meaning in order to illustrate the way in which the inherently rigid and polarized tonal system of the Classical style marginalized digressions to an unusual key. These digressions stand apart from the twin poles of the tonic and the dominant, thereby earning Tovey's designation as "purple patches." By extending Tovey's analytical model to all of Haydn's string quartets, I have uncovered three compelling facts: 1) an unusual structure, unlike the majority of works written in the Classical period, appears in twenty five of Haydn's quartets; 3 2) an harmonic digression, described by Tovey as a "purple patch," appears in sixteen of these quartets; ${ }^{4}$ and 3 ) these unusual works, which are known as "three-part expositions," are propelled the dynamic harmonies of the purple patch, a function that heretofore has gone unnoticed in the scholarly literature. ${ }^{5}$

3. Haydn wrote 68 string quartets in total, each of which comprises four movements. For the purposes of this study, I will only consider the first movements of these quartets.

4. The remaining nine "unusual" works include phenomena that reproduce the general function of the purple patch, namely the anticipation and simultaneous delay of the new key. For more on the difference between the pieces with and without a purple patch, see the author's dissertation, Three-Part Expositions in the String Quartets of Joseph Haydn. Ph.D. Dissertation, Brandeis University.

5. The first scholars to seriously describe the three-part exposition were Jens Peter Larsen and Michelle Fillion. Larsen first defined the term, gave an overview and cited a few examples, while Fillion produced the first in-depth study of the form in Haydn's piano sonatas. See especially Larsen's "Sonatenform-Probleme," in Festschrift Friedrich Blume zum 70 Geburtstag, ed. Anna Amalie Abert and Wilhelm Pfannkuch (Kassel: Barenreither, 1963), 221-30; it was later translated into English as "Sonata Form Problems," in Handel, Haydn, and the Viennese Classical Style, trans. Ulrich Krämer (Ann Arbor: UMI Research Press, 1998), 269-79. See also Michelle Fillion, "Sonata Exposition Procedures in Haydn's Keyboard Sonatas," Haydn Studies. 
The general structure under consideration here is known as "sonata form." It appears in a majority of the compositions written during the Classical period (c.1750-1810), and Joseph Haydn was one of the earliest Classical composers to utilize it. Despite its predominance at the time, a "typical" sonata form was not codified until later in the nineteenth century under the next generation of composers and theorists. ${ }^{6}$ During the time of Haydn's compositional practice, however, sonata form existed in many different variations. The most prominent one is known as the "two-part" exposition, whereas "monothematic" and "threepart" expositions were more rare. ${ }^{7}$ In fact, the latter structure seems to be restricted to Haydn's oeuvre, rarely appearing in the works of Beethoven and never in Mozart. According to James Hepokoski and Warren Darcy, "the two-part exposition was by far the most normative model of the late eighteenth century." Given the disparity in the rate of appearance between the two- and three-part expositions, it is safe to assume that a typical listener in the late eighteenth century might expect to hear a two-part exposition at any particular performance. This presents us with an opportunity: if one were to provide such a typical listener with a three-part exposition, in lieu of the expected two-part form, what might result? In other words, why might a composer of Haydn's stature use such a strategy? The main concern of this paper, therefore, is an investigation of what differentiates the three-part exposition (i.e., the atypical form) from the two-part exposition.

决 弥

Proceedings of the International Haydn Congress, Washington, D.C., 1975, ed. Jens Peter Larsen, Howard Serwer, and James Webster (New York: Norton: 1981), 475-81.

6. A.B. Marx is generally considered to be the first theorist to describe sonata form. See his text, Die Lehre von der musikalischen Komposition, 5th ed., 3 vols. (Leipzig: Breitkopf und Härtel, 1879). See also Scott Burnham, Aesthetics, Theory and History in the Works of A. B. Marx, Ph.D. Diss., Brandeis University, 1988; and Burnham, "The Role of Sonata Form in A. B. Marx's Theory of Form," The Journal of Music Theory 33 (1989): 247-71.

7. Fillion found that roughly one third of Haydn's piano sonatas included a threepart exposition; see Fillion, "Haydn's Keyboard Sonatas." Similarly, I have identified a three-part exposition in just under fifty percent of Haydn's quartets; see Ludwig, Three-Part Expositions.

8. James Hepokoski and Warren Darcy, "The Medial Caesura and Its Role in the Eighteenth-Century Sonata Exposition,” Music Theory Spectrum 19.2 (Autumn 1997): 117 . 
In the triumvirate of major Classical composers, Haydn antedates Mozart's birth by twenty-four years and Beethoven's by thirty-eight. His role as the father of the string quartet and the symphony is unquestioned and his experimentations with musical structure outlined its various possibilities for his counterparts. Haydn began composing during an era of tremendous change: in the middle of the eighteenth century, the Baroque period-popularized by the ornate and complex music of J.S. Bach and George Handel-began to wane. It was eventually supplanted by the new style galant, which featured a simpler melodic type of music. This new style featured shorter, more discrete units that, when combined together, lent an almost architectural quality to the finished work. A new sense of proportion and design became a defining trait of the new Classical style.

Within this period, Haydn composed works that exhibited a unique-some might say idiosyncratic-character. He experimented with various compositional techniques, often drawing on elements from styles both old and new. But his inclusive approach created works that were considered exceptions to, rather than illustrations of, the rule. Edward Cone described Haydn's experimentations thusly: "Haydn was attacking certain conventional presuppositions of the Classical style from the inside, since he had grown up within it-or rather, it had grown around him." ${ }^{\text {9 }}$ What attracted Haydn to such unusual forms? Were they the result of his isolation at Prince Esterhazy's castle? Or a deliberate attempt to mislead his listening audience? One may only speculate as to the reasons for Haydn's experimentation; it is unquestionable, however, that he was drawn to musical structures unlike those of his fellow composers.

It is important to note that our judgment of musical form in the eighteenth century is informed by decades - if not centuries-of musical thought. ${ }^{10}$ Currently, the ubiquity of sonata form is commensurate

9. Edward T. Cone, "The Uses of Convention: Stravinsky and His Models," Musical Quarterly, 48.3 (July 1962), 295.

10. The current resurgence in the Formenlehre tradition traces back to William Caplin's authoritative text Classical Form: A Theory of Formal Functions for the Instrumental Music of Haydn, Mozart, and Beethoven (New York: Oxford University Press, 1998). Since then, James Hepokoski and Warren Darcy have contributed a similar-and larger-tome, Elements of Sonata Theory: Norms, Types, and Deformations in the Late-Eighteenth-Century Sonata (New York: Oxford University Press, 2006). 
with its presence in the scholarly literature, but the conventional view of sonata form gives prominence to the thematic structure at the expense of the harmonic one. This conception of the form was codified only in the nineteenth century in the generation that practiced after Haydn, Mozart and Beethoven. Sonata form's codification came at the expense of a much richer and more varied history: in fact, the description of sonata form as a tonal process, rather than a thematic one, is more historically accurate. According to Leonard Ratner, the "thematic approach betrays a lack of historical perspective...In classic theory, the standard scheme of a first movement was expressed as a series of harmonic relationships. Virtually all references to form describe or allude to an underlying harmonic plan." ${ }^{11}$ With this in mind, it is necessary to delineate the general outlines of sonata form (see fig. 1). Broadly speaking, sonata form divides into three large sections (the exposition, development and recapitulation) supported by a fundamental bipartite tonal structure. As we will see, a sonata form functions in a manner familiar to many readers.

A typical exposition (i.e. two-part exposition) comprises the introduction of thematic and tonal materials. The first theme appears in the key of the tonic; the second theme in the key of the dominant. ${ }^{12}$ In addition, a clear demarcation accompanies the thematic material of these two areas, too. The first theme is loud and aggressive, while the second theme is soft and lyrical. Likewise, the tonalities occupy different ends of the harmonic spectrum, too, so much so that when the key of the dominant is introduced it is perceived as a hostile

11. Leonard Ratner, "Harmonic Aspects of Classic Form," Journal of the American Musicological Society 2.3 (Autumn 1949): 160.

12. The tonal system, especially as it pertains to the sonata form in the Classical period, is similar in design to our solar system. Both systems contain a central home base around which secondary objects rotate. The sun's equivalent is the key of the tonic: it is most likely the first and last sounds that the listener will hear; it is built on the first degree of the "controlling" scale on which the work is based; and it does not undergo a transformation, providing a steady source of what the listener perceives as safety or home. Extending the analogy further, the earth is the key of the dominant: it is the dynamic driver of pieces, especially those in sonata form; it is built on the fifth degree of the scale; and its resolution is of utmost importance to the sonata form as a whole. Finally, the moon is the purple patch: it rotates around the earth, as the earth and the moon simultaneously rotate around the sun; it manipulates the way in which the key of the dominant functions, just as the moon determines the tides on Earth. 
FIGURE 1

\section{Typical Outline of Sonata Form}

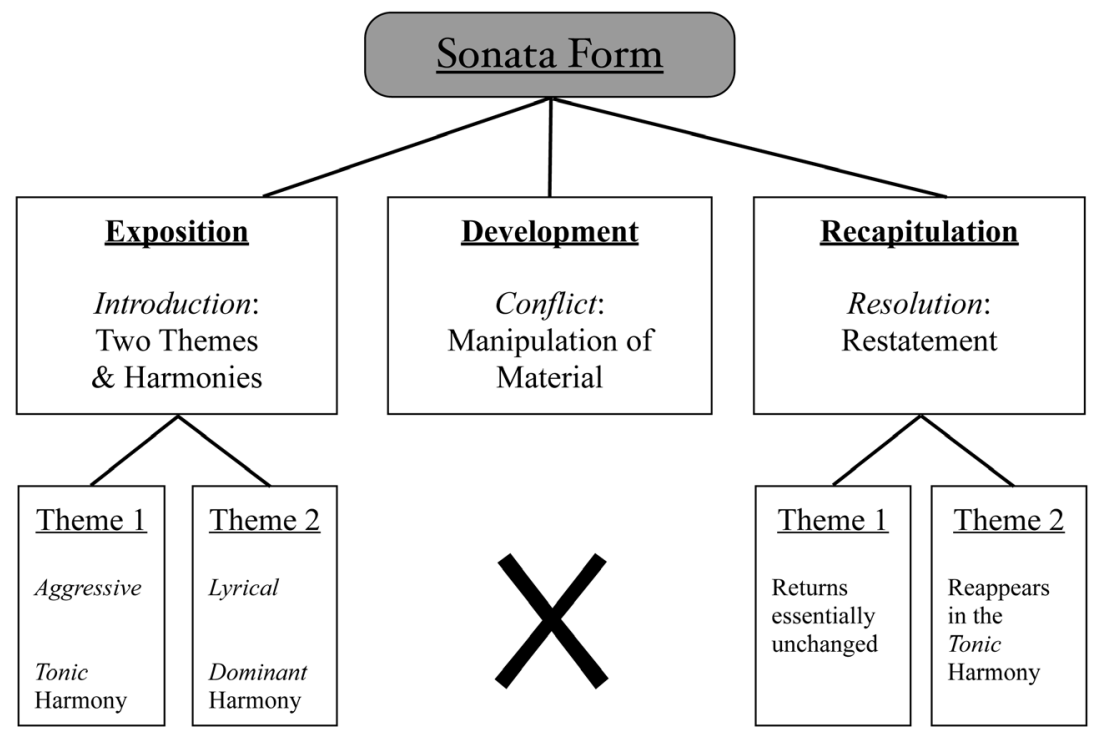

invader, overtaking the previously accepted key of the tonic. The double conflict between the first and second theme and the keys of the tonic and the dominant provides an initial measure of drama to the exposition. ${ }^{13}$

The drama of the exposition is merely a prelude to what takes place in the development. In this middle section, the security of the home key is destroyed, as is the safe and controlled presentation of thematic material. In short, the development escalates the dramatic intensity of the movement. The development abuts the recapitulation, the latter of which functions as a bulwark against the excesses of the former. Whereas drama increases in the development section, it is resolved in the recapitulation. The first theme returns essentially unchanged and in the original tonic while the second theme, which originally took place in the key of the dominant, now appears in the tonic. The transposition of the second theme from the dominant to the tonic

13. For more on the "drama" of sonata form, see Charles Rosen's Sonata Forms (New York: Norton, 1988). 
provides the ultimate closure for any sonata form. The resolution of non-tonic material is vital: without it, any sonata form will be perceived as incomplete..$^{14}$

$$
\text { 许 弥 }
$$

Despite its ubiquity in modern-day analytical circles, the tonal process of a typical two-part exposition does not extend to all works written in the Classical style. As I mentioned above, sonata form existed in many different types prior to its eventual codification in the nineteenth century, and Haydn stands opposed to his counterpartsMozart and Beethoven-by utilizing the three-part exposition. In the Classical period, this structure was truly a viable option, whereas today it is thought of as atypical or nonstandard. This perspective is not unfounded: the tonal process of a three-part exposition deviates substantially from the two-part exposition. In order to delineate the difference, we will examine Haydn's sixty-first quartet, known as Op. 76 , no. 1, in G major.

Note the difference in themes: the first theme begins with solo statements (starting in bar 3) before it gradually coalesces into a fuller texture (around bar 26). Although the texture changes gradually, the harmony does not: the original tonic underscores the entire first theme (mm. 1-32) in order to provide the listener with a clear sense of harmony. In the second theme, the thematic material is contained solely within the top voice (mm. 73-80), and its lyrical nature is a stark contrast from the earlier learned-almost stilted-first theme. Clearly, these two themes occupy opposite ends of the thematic and tonal spectrum: the first theme, which features a plodding nature, is set entirely in the key of the tonic; the second theme is lyrical and melodic in style and set in the key of the dominant.

The material found in between measures 32 and 72 is what makes this exposition exceptional and unique. Haydn knew that his audience was aware of, and even expected, a bifurcation of thematic and tonal traits in the exposition. Moreover, even slight disturbances in a form

14. Edward Cone was the first to formulate this process as follows: "[I]mportant statements made in a key other than the tonic must either be restated in the tonic, or brought into a closer relation with the tonic, before the movement ends." See his Musical Form and Musical Performance (New York: Norton, 1968), 76-77. 
FIGURE 2

Comparison of Two- and Three-Part Expositions

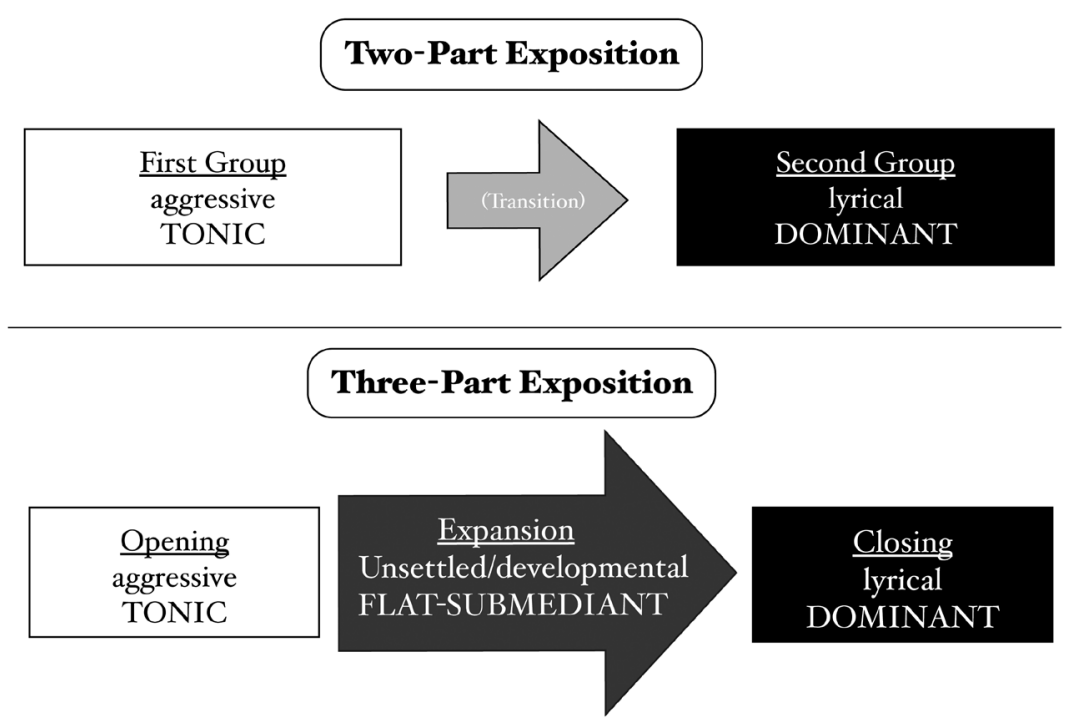

might affect the potential listeners in such a way as to thwart their expectations (see fig. 2). To this end, Haydn created the general structure of a three-part exposition. Instead of a typical, two-part structure, the three-part exposition includes a new, middle section that disrupts the expected progression. The inherent dynamism of this structure is generated by the contrast between the inner and outer sections. The inner section-known as the expansion section-is unlike anything that normally takes place in a two-part exposition; in fact, it most resembles the development section, both by avoiding the tonic key and sequentially treating motivic material. The expansion section provides the structure with conflict or "motion," thereby falling in between the outer static sections of rest. In one sense, then, the three-part exposition mirrors sonata form in the fact that its middle third acts as a dynamic catalyst. The exposition under consideration here includes such a dynamic middle section in between the two thematic and tonal areas discussed above (see, for example, measures 33 to 71 ).

From a structural point-of-view, the first half of the exposition is fairly confusing: where is the beginning of the second-theme area? The situation becomes clearer around the middle point (starting in $\mathrm{m} .5 \mathrm{O}$, 
especially in mm. 56-64). One is immediately struck by the virtuosic, almost athletic, quality of the motivic material. The obsessively repeated motive generates the drama of this passage, and it dominates the last half of this passage. The climax is unique in a number of ways: first, the melodic material is condensed down to a single motive, repeated continuously; second, the texture is reduced to a unison, in which all four voices play the exact same material; and third, the repeated motive supports a rare harmony called the "flat submediant" that is also known as a "flat-six" chord. ${ }^{15}$

The presence of this harmony at this location in a sonata form, when one is expecting the key of the dominant, is, for Donald Tovey, a purple patch, because it stands apart from other harmonic areas in the work and functions like a digression. But this purple patch is more than a digression: it serves to simultaneously anticipate and avoid the key of the dominant, which to the educated listener is the ultimate goal of any sonata-form exposition. Haydn's contemporary audiences would certainly have recognized that this purple patch, built on the flat submediant, sounded out of place. It provides a wedge in between the expected polarity of tonic and dominant, thereby disrupting the entire expectation of a two-part exposition. Haydn inserted this rare and unusual tonality as another way to provoke his audience by thwarting their expectations.

It is clear that Haydn was a truly self-conscious composer. He knew that a typical listener in the late eighteenth century came to a performance with a set of preconceived expectations in mind. By promising one thing and delivering another, Haydn manifested in his compositional output a prodigious sense of irony and humor. For example, in 1772 Haydn not-so-subtly implored his employer, Prince Esterhazy, to release his musicians from their extended holiday contract. He did so by writing into the score of his Symphony 45, in F\# minor, that the

15. A typical sixth chord (i.e., one that was built on the sixth degree of the dominant scale: B, which occurs six steps above D) would not be considered completely unusual. The addition of the "flat" pulls the sixth chord out of its normally occurring harmony (what is called diatonic series) and into a more "unnatural" field of associations (what is called the chromatic series). 
musicians should leave the stage, one by one, until only two violinists remained on the stage. The Prince released them the next day. In 1781, Haydn wrote a string quartet (Op. 33, no. 2, in E-flat Major) in which the ending refuses to end. Like a skipping record, the final phrase repeats over and over again until it finally dissipates, leaving the audience in a state of suspended disbelief. To this day, this quartet is known as "The Joke," and still produces nervous glances amongst its audiences. $^{16}$

Both of these works demonstrate Haydn's ability to manipulate his audience. The first movement of the work under consideration here, on the other hand, is more subtle in its effect. Although it begins like a typical, two-part exposition, the final product is much different. The true second theme is delayed by a dynamic middle section, thus disrupting the expectation of a typical outcome. I believe that the purple patch of unusual harmony is the key to unlocking this form. This study is the first to reveal the connection between the dramatic, development-like middle section of the three-part exposition and the chromatic passage of material in the flat-submediant that Tovey called a "purple patch." Haydn has underlined this section three times over using extreme versions of harmony, melody and texture-all the major elements of music-thereby guaranteeing that the disruptive middle section will receive its due notice.

Haydn's interest in these disruptions developed over years of musical activity. Although this unique formal experiment failed to find a foothold in the generation of composers following Haydn, its adventurous approach to tonal structure precipitated developments in the nineteenth century. A more complete understanding of the three-part exposition, and its inherently dynamic middle section, will help to better illuminate the evolution and transformation of musical style in both the Classical and Romantic eras.

16. Issues of irony and humor in the works of Haydn are a particularly fruitful field: for a definitive account, see Mark Evan Bonds, "Haydn, Laurence Sterne, and the Origins of Musical Irony," Journal of the American Musicological Society 44.1 (Spring, 1991), 57-91; see also Gretchen A. Wheelock, Wit, Humor, and the Instrumental Music of Joseph Haydn, Ph.D. diss., Yale University, 1979. 